\title{
ANALYSIS OF EMISSION AND VIBRONIC TRANSITIONS IN URANIUM(3+) DOPED $\mathrm{Cs}_{2} \mathrm{LiYCl}_{6}$ SINGLE CRYSTALS
}

\author{
M. KarbowiaK ${ }^{a}$, E. Simoni ${ }^{b}$, J. DrożdżYŃSKI ${ }^{a}$ AND S. HUBERT ${ }^{b}$ \\ a Faculty of Chemistry, University of Wroclaw, Joliot-Curie 14, 50-383 Wroclaw, Poland \\ ${ }^{b}$ Institut de Physique Nucléaire, Groupe de Radiochemie \\ B.P. No. 1, 91406 Orsay Cedex, France
}

\begin{abstract}
Uranium(3+) doped single crystals of $\mathrm{Cs}_{2} \mathrm{LiYCl}_{6}$ with a 0.3 and $2.0 \%$ $\mathrm{U}^{3+}$ concentration have been obtained by the Bridgman-Stockbarger method. Luminescence spectra of the crystals were recorded at 27 and $15 \mathrm{~K}$, respectively. The emission bands observed in the visible and near infrared regions have been assigned to transitions from the ${ }^{4} I_{11 / 2},{ }^{4} F_{3 / 2}$, and ${ }^{4} G_{7 / 2}$ levels to the ${ }^{4} I_{9 / 2}$ ground level.

PACS ^umbers: 33.50.Dq, 33.55.Be, 71.70.Ej, 81.10.Fq
\end{abstract}

\section{Introduction}

In this paper we present an analysis of luminescence spectra of uranium(3+) doped $\mathrm{Cs}_{2} \mathrm{LiYCl}_{6}$ single crystals at 15 and $45 \mathrm{~K}$. A preliminary study of similar, $\mathrm{Cs}_{2} \mathrm{NaYCl}_{6}: \mathrm{U}^{3+}$ single crystals, has been presented earlier [1]. Since in the investigated elpasolite crystals the central metal ion posses the $O_{h}$ site symmetry vibronic transitions are an order of magnitude stronger than the electric dipole ones and are very suitable for spectroscopic investigations.

\section{Experimental}

Uranium $(3+)$ doped single crystals of $\mathrm{Cs}_{2} \mathrm{LiYCl}_{6}$ with a $0.1 \%$ uranium concentration were grown by the Bridgman-Stockbarger method using $\mathrm{Cs}_{2} \mathrm{LiUCl}_{6}$ as the doping substance. Polished plates of $c a .6 \mathrm{~mm}$ in diameter and 1 to $5 \mathrm{~mm}$ thick were used for measurements of the luminescence spectra.

For the preparation of $\mathrm{Cs}_{2} \mathrm{LiUCl}_{6}$ a well-grinded stoichiometric mixture of $\mathrm{CsCl}, \mathrm{NaCl}$ and $\mathrm{NH}_{4} \mathrm{UCl}_{4} \cdot 4 \mathrm{H}_{2} \mathrm{O}$ [2] was first heated in a quartz tube at a non-static vacuum of $c a \cdot 10^{-6} \mathrm{hPa}$. In order to convert $\mathrm{NH}_{4} \mathrm{UCl}_{4} \cdot 4 \mathrm{H}_{2} \mathrm{O}$ into $\mathrm{UCl}_{3}$, the temperature of the furnace was slowly increased from 20 to $350^{\circ} \mathrm{C}$. Next the tube was sealed off and the mixture heated for $24 \mathrm{~h}$ at $300^{\circ} \mathrm{C}$. Subsequently the temperature was slowly decreased and the mixture heated at $400^{\circ} \mathrm{C}$ for 7 days. An ink blue fine crystalline powder was obtained. The compound was stored under nitrogen in 
sealed tubes. $\mathrm{Cs}_{2} \mathrm{IiYCl}_{6}$ was obtained by evaporating stoichiometric anounts of $\mathrm{Cs}_{2} \mathrm{CO}_{3}, \mathrm{LiCl}$ and $\mathrm{Y}_{2} \mathrm{O}_{3}$ from a $10 \mathrm{M} \mathrm{ICl}$ solution.

The emission spectra were recorded at $15 \mathrm{~K}$ and $45 \mathrm{~K}$ on a Jobin-Yvon IIR 1000 monochromator using an Oxford cryogenic cryostat. As detectors the Hamamatsu R928 photomultiplier and a PbS diode were used. The emission spectrum was obtained by selective excitation of particular $f-f$ lines with a YAG laser pumped dye laser.

\section{Results and discussion}

In Figs. 1, 2 the emission spectra of the $\mathrm{Cs}_{2} \mathrm{LiYCl}_{6}: \mathrm{U}^{3+}$ single crystals in the visible and infrared range are presented. The bands observed in the 12000$13000 \mathrm{~cm}^{-1}$ range were assigned to transitions from the ${ }^{4} G_{7 / 2}$ level to the three crystal-field components of the ${ }^{4} I_{9 / 2}$ ground level. In this range one does not observe zcro- phonon transitions but only the vibronic structures connected with these transitions. The positions of the zero-phonon transitions were determined basing on the Stokes and anti-Stokes transition symmetry as well as on an analysis of the observed ripetitive vibronic structures.

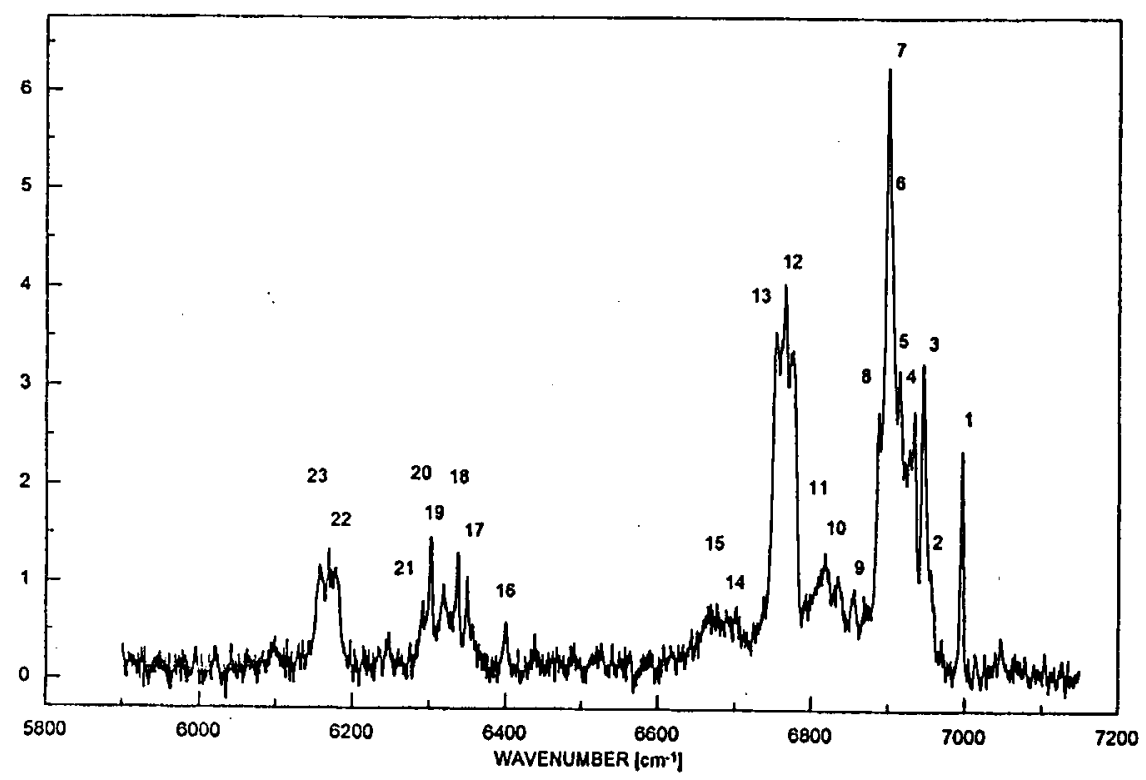

Fig. 1. Flnorescence spectra showing the ${ }^{4} F_{3 / 2} \rightarrow{ }^{4} I_{9 / 2}$ transitions at $15 \mathrm{~K}$ in the $\mathrm{U}^{3+}: \mathrm{Cs}_{2} \mathrm{IiYCl}_{6}$ crystials.

A similar rich and well-resolved vibronic structure was observed in the 6000 $7000 \mathrm{~cm}^{-1}$ range from which emission to the three crystal-field components of the ground manifold $a \Gamma_{8}, \Gamma_{6}$ and $b \Gamma_{8}$ takes place from the lowest crystal-field component of the ${ }^{4} F_{3 / 2}$ level. In this range one may observe also two zero-phonon lines most probably connected with magnetic-dipole transitions at $6995 \mathrm{~cm}^{-1}$ 
TABLE ${ }^{4} F_{3 / 2} \rightarrow{ }^{4} I_{9 / 2}$ and ${ }^{4} G_{7 / 2} \rightarrow{ }^{4} I_{9 / 2}$ luminescence spectra of the $\mathrm{U}^{3+}: \mathrm{Cs}_{2} \mathrm{LiYCl}_{6}$ crystals at $15 \mathrm{~K}$.

\begin{tabular}{|c|c|c|c|c|c|}
\hline \multicolumn{3}{|c|}{${ }^{4} G_{7 / 2} \rightarrow{ }^{1 / 9 / 2}$ transition } & \multicolumn{3}{|c|}{${ }^{4} F_{3 / 2} \rightarrow{ }^{4} I_{9 / 2}$ transition } \\
\hline Line $^{a}$ & $\begin{array}{c}\text { Wave number } \\
{\left[\mathrm{cm}^{-1}\right]}\end{array}$ & $\begin{array}{c}\begin{array}{c}\text { Assignment of lower } \\
\text { level }^{\text {b }}\end{array} \\
\end{array}$ & Line & $\begin{array}{c}\text { Wave number } \\
{\left[\mathrm{cm}^{-1}\right]}\end{array}$ & $\begin{array}{c}\text { Assigment of lower } \\
\text { levelc }\end{array}$ \\
\hline (1) & 12967 & $a \Gamma_{8}$ & $\begin{array}{l}1 \\
2\end{array}$ & $\begin{array}{l}6995 \\
6955\end{array}$ & $\begin{array}{c}a \Gamma_{8} \\
a \Gamma_{8}+S_{5}(40)\end{array}$ \\
\hline 2 & 12918 & $a \Gamma_{8}+S_{9}(50)$ & 3 & 6945 & $a \Gamma_{8}+S_{9}(50)$ \\
\hline 3 & 12902 & $a \Gamma_{8}+S_{10}(65)$ & 4 & 6933 & $a \Gamma_{8}+S_{10}(62)$ \\
\hline 4 & 12884 & $a \Gamma_{8}+S_{10}(83)$ & 5 & 6914 & $a \Gamma_{8}+S_{10}(81)$ \\
\hline (5) & 12874 & $\Gamma_{6}$ & 6 & 6902 & $\Gamma_{6}$ \\
\hline 6 & 12872 & $a \Gamma_{8}+S_{7}(95)$ & $\begin{array}{l}7 \\
8\end{array}$ & $\begin{array}{l}6898 \\
6887\end{array}$ & $\begin{array}{c}a \Gamma_{8}+S_{7}(97) \\
a \Gamma_{8}+S_{7}(108)\end{array}$ \\
\hline 7 & $12 S 28$ & $\Gamma_{\epsilon}+S_{9}(46)$ & $\begin{array}{c}9 \\
10 \\
11\end{array}$ & $\begin{array}{l}6855 \\
6834 \\
6817\end{array}$ & $\begin{array}{c}\Gamma_{6}+S_{9}(47) \\
\Gamma_{6}+S_{10}(68) \\
\Gamma_{6}+S_{10}(88)\end{array}$ \\
\hline 8 & 12777 & $\Gamma_{6}+S_{7}(97)$ & & & \\
\hline 9 & 12735 & $a \Gamma_{8}+S_{6}, S_{2} Z B(232)$ & 12 & 6764 & $a \Gamma_{8}+S_{6}, S_{2} Z B(231)$ \\
\hline 10 & 12726 & $a \Gamma_{8}+S_{6}(241)$ & 13 & 6752 & $a \Gamma_{8}+S_{6}(243)$ \\
\hline 11 & $126: 19$ & $\Gamma_{6}+S_{6}, S_{2} Z B(225)$ & 14 & 6701 & $\Gamma_{6}+S_{6}, S_{2} Z B(201)$ \\
\hline 12 & $126: 32$ & $\Gamma_{6}+S_{6}(242)$ & 15 & 6668 & $\Gamma_{6}+S_{6}(234)$ \\
\hline (13) & 12371 & $b \Gamma_{8}$ & 16 & 6400 & $6 \Gamma_{8}$ \\
\hline 14 & 12321 & $b \Gamma_{8}+S_{9}(50)$ & 17 & 6350 & $b \Gamma_{8}+S_{9}(50)$ \\
\hline 15 & 12305 & $6 \Gamma_{8}+S_{10}(66)$ & 18 & 6337 & $b \Gamma_{8}+S_{10}(63)$ \\
\hline 16 & 12289 & $b \Gamma_{8}+S_{10}(82)$ & 19 & 6319 & $b \Gamma_{8}+S_{10}(81)$ \\
\hline 17 & 12274 & $b \Gamma_{8}+S_{7}(97)$ & 20 & 6302 & $b \Gamma_{8}+S_{7}(\mathbf{9 8})$ \\
\hline 18 & 12242 & $b \Gamma_{8}+S_{7}(129)$ & 21 & 6291 & $b \Gamma_{8}+S_{7}(109)$ \\
\hline 19 & 12150 & $b \Gamma_{8}+S_{6}, S_{2} Z B(221)$ & 22 & 6169 & $b \Gamma_{8}+S_{6}, S_{2} Z B(231)$ \\
\hline 20 & 12128 & $6 \Gamma_{8}+S_{6}(243)$ & 23 & 6157 & $b \Gamma_{8}+S_{6}(243)$ \\
\hline
\end{tabular}

a Lines in brackets are zero-phonon lines, not observed in the spectra.

${ }^{b}$ The upper level is ${ }^{4} C_{7 / 2}\left(\Gamma_{7}\right)$.

c The upper level is $4 F_{3 / 2}\left(\Gamma_{8}\right)$.

$\left(\Gamma_{\mathrm{S}} \rightarrow a \Gamma_{\mathrm{S}}\right)$ and $6400 \mathrm{~cm}^{-1}\left(\Gamma_{\mathrm{8}} \rightarrow b \Gamma_{\mathrm{8}}\right)$. The third one is most probably covered by the strong vibronic side bands.

In the $4000-4400 \mathrm{~cm}^{-1}$ spectral range one observes together with some low intensity vibronic transitions, two distinct zero-phonon lines connected with the forbidden electric-dipole transitions from the lowest crystal-field level of the ${ }^{4} I_{11 / 2}$ manifold to the excited crystal-field components of the ground level.

The performed analysis enabled the determination of the energies of the excited components of the ground level equal to $93\left(\Gamma_{6}\right)$ and $595\left(b \Gamma_{8}\right) \mathrm{cm}^{-1}$ as well as the assignment of the observed vibronic modes which are summarized in Table. In the assignment of the vibronic bands we followed the earlier reported analysis of $\mathrm{Nd}^{3+}[3]$ and $\mathrm{U}^{3+}[4]$ ions in $\mathrm{Cs}_{2} \mathrm{NaYCl}_{6}$ single crystals. 


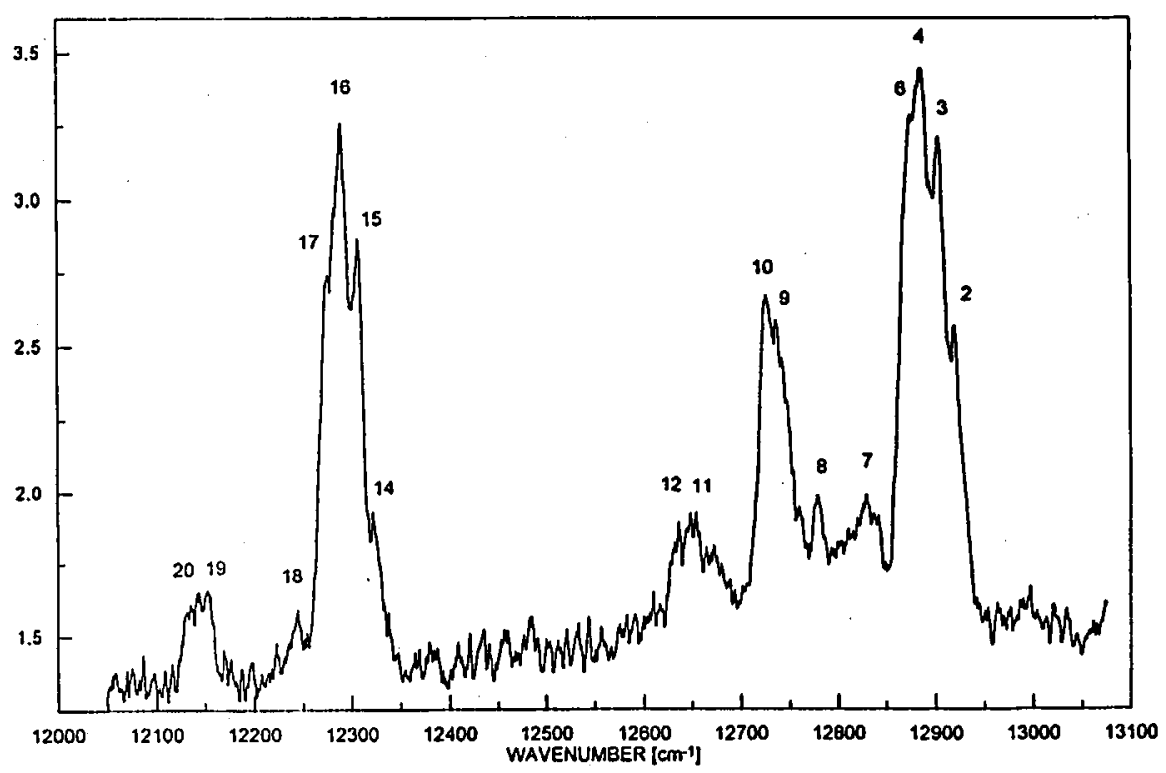

Fig. 2. Fluorescence spectra showing the ${ }^{4} G_{7 / 2} \rightarrow{ }^{4} I_{9 / 2}$ transitions at $15 \mathrm{~K}$ in the $\mathrm{U}^{3+}: \mathrm{Cs}_{2} \mathrm{LiYCl}_{6}$ crystals.

\section{References}

[1] P.J. Dereń, W. Stręk, J. Drożdżyński, J. Appl. Spectrosc. 62, 58 (1995).

[2] J. Drożdży'iski, J. Less-Common Met. 138, 271 (1988).

[3] P.A. Tanner, J. Quagliano, F.S. Richardson, J. Chem. Soc. Faraday Trans. 87, 1707 (1991).

[4] P.A. Tanner, J. Mol. Struct. 355, 299 (1995). 